\title{
RESILIENT COMMUNITIES. SOCIAL INFRASTRUCTURES FOR SUSTAINABLE GROWTH OF URBAN AREAS. A CASE STUDY
}

\author{
A. BOERI ${ }^{1}$, D. LONGO $^{1}$, V. GIANFRATE ${ }^{1} \&$ V. LORENZO ${ }^{2}$ \\ ${ }^{1}$ Department of Architecture, University of Bologna, Italy. \\ ${ }^{2}$ The Umbra Institute, Italy.
}

\begin{abstract}
Climate change, natural and human-made disasters, overcrowding spaces, waste production, and energy access are just a few of issues that our cities have to deal with. At the same time, cities offer a promising intervention field to foster collaborations in planning and managing sustainable infrastructure for sustainable growth.

Creating resilient cities has both social and physical dimensions. Reinforcing local identity and culture contributes to positive relationships among individuals, improving their collective ability to face change.

The City of Bologna is engaged in the definition of pilot actions to promote the active participation of stakeholders for the acceleration of Local Urban Environment Adaptation Plan for a Resilient City, linked to Common Goods Regulation: act together (collective regeneration of urban spaces), live together (new welfare, health and well-being), grow together (collaborative spaces for innovative jobs and enterprises). In this context the Research Group of the University of Bologna is involved in the development of a flexible and replicable methodology to support the transition to more sustainable urban context. This paper illustrates this methodology and the experimental study carried on to establish active mechanisms of engagement of citizens, associations, creative communities, private bodies, aiming at increasing community resilience and sensitivity and fostering sustainable growth.

Keywords: community based approach, historic city, living lab, resilience.
\end{abstract}

\section{CITIES AND CLIMATE CHANGE: PART OF THE PROBLEM, PART OF THE SOLUTION}

Over half of the world's population lives in cities, almost 4 billion people, a number that is expected to grow to 5.1 billion by 2,030 (studies by UNDESA and ICLEI $[1,2]$ ) and Europe, at present, is the world's most urbanized continent.

Urban areas, with their high concentration of population, industries and infrastructure, concentrate also risks in cities, which therefore become more vulnerable to shocks and stresses and are likely to face the most severe impacts of climate change. Moreover, the increasing global competition for energy and resources is likely to combine with the effects of climate change to impact disproportionally on the poorest and most vulnerable populations. This happens also in Europe and in its cities, where inequalities are intensifying due to a number of demographic and economic phenomena, notably ageing (with many elderly people being less able to cope with environmental impacts), increasing ethnic diversity and rising numbers of people experiencing poverty and/or social exclusion. These developments are inter-related and combined to produce different configurations of environmental vulnerability in a given city [2]. 
The effects of urbanization and climate change are converging in dangerous ways with unprecedented negative impacts upon quality of life, and economic and social stability as defined by UNHABITAT [3] and presenting particular challenges for cities.

The reputations of cities as service providers are posed in serious threat as well as their ability to meet their own targets for growth and development, and despite many governments and communities have strategies in place to deal with routine climate variability, projected climate change increasing climate variability will require sound management (and dedicated planning and funding), in order to ensure resilience and enable sustainable growth into the future [4].

However, it is increasingly recognized that because cities are central to the ways in which the vulnerabilities and risks of climate change are produced and large contributors to the underlying causes (e.g. GHG emissions), cities can also be part of the solution to address climate change possibilities and challenges [5]. The same concentration of people, industrial and cultural activities, results in fact in an equally compelling set of opportunities that can make cities crucibles of innovation [3], where to catalyze insurgent strategies promoting reductions in greenhouse gas emissions, testing coping mechanisms, as disaster warning systems and mutual self-help networks, and improving social and economic equity, ultimately reducing vulnerability to climate change impacts through mitigation and adaptation measures and sustainable urban regeneration.

To attempt to address climate change and global warming, many cities all around the world are currently developing projects and urban policies focusing both on mitigation measures to reduce greenhouse gases (GHG) emissions, in reason of cities' large contribution to these kind of emissions, and on the development of local adaptation strategies to respond to actual climate impacts and reduce existing vulnerabilities of the territory (through reactive and preventive adaptation), introducing the concept of Resilient Cities and Communities.

Resilience assumes that climate change is occurring, recognizing uncertainty, change and crisis as normal but instead of aiming to sustain the status quo, tries to improve the ability of individuals, communities, or systems to recognize and adapt to disturbances, to overcome them and eventually come out stronger and transformed, changing the stability landscape [6] and creating new system pathways when ecological, economic or social structures make the existing system untenable, as elaborated by Walker et al. [7], Folke et al. [8].

The genealogy of the concept of resilience has evolved, thus, from its initial focus on the persistence of ecological system functions, through an emphasis on the adaptability of coupled social-ecological systems, to its most recent reorientation towards addressing the transformability of society in the face of global change [9].

A Resilient City is prepared to absorb and recover from any shock or stress while maintaining its essential functions, structures, and identity, as well as adapting and thriving in the face of continual change. A resilient city supports, in fact, the development of greater resilience in its institutions, infrastructure, and social and economic life, reducing vulnerability to extreme events and responds creatively to economic, social and environmental change in order to increase their long-term sustainability. This requires evidence-based, long-term, and inclusive strategies that take an integrated, systems approach to reduce vulnerability and disaster risk while increasing adaptive capacity in line with sustainable development goals [2].

Cities can accelerate transition pathways, implementing climate proof physical infrastructures and defining new governance models and urban policies, to increase community resilience and foster sustainable growth. 


\section{THE SOCIAL DIMENSIONS OF RESILIENCE: DIFFERENT APPROACHES}

Creating resilient cities has both social and physical dimensions. The Rockefeller Foundation lists "qualities" of resilient cities like reflective, robust, redundant, flexible, resourceful, inclusive and integrated, following ARUP Report [10]. The Stockholm Resilience Institute identifies "principles" for building resilience in coupled socio-ecological systems, such as maintaining diversity and redundancy, encouraging learning, managing connectivity, promoting polycentric governance systems and broadening participation, calling municipalities to seek multiple modes of governing for climate change. The physical dimensions of a resilient city are inherent to urban form, infrastructure, systems and services in the ways these impact coupled socio-ecological system, (Stockolm Environmental Center [11]) and require dedicated programming, knowledge and funding. The social dimensions relay on the coping, adaptive and transformative capacities [9] of local communities to deal with threats, and can be improved by reinforcing local identity and culture [5], fostering participation through active engagement of all relevant stakeholders [12] and allowing the presence of redundancy, to provide overlapping functions and a diversity of responses of groups of actors with different roles and different strengths, which enhances the flourishing of creativity and adaptability.

Addressing climate change, in fact, requires an "unprecedented level of cooperation, not only between countries, but also between different levels of Governments, the private sector" and non-state actors (corporations, NGOs, international foundations, community groups), increasingly involved in responding to climate change [13]. The social dimensions of resilience in these "climate change experiments" - a concept that is bound to governance experiments, the role of niches and grassroots innovations in socio-technical regimes, and the notion of "urban laboratories", defined by Castàn Broto and Bulkeley [14] and intended as interventions to try out new ideas and methods in the context of future uncertainties, which is the case of almost all attempts of urban climate change adaptation in place, being the issue so recent - can be achieved through different approaches, depending on which methods are employed to reach and engage citizens and on who leads urban initiatives and actions.

For what concerns the methods to reach and engage citizens, broaden participation and improve the social dimensions of resilience, the following different approaches can be identified:

- Stakeholder engagement and Multi-level process. Basic form of engagement at the urban scale for climate governance, typically takes place in ICLEI program where local governments participating in the milestone process, convene meetings to share information with the general public and obtain input on plans. The Multi-level process is obtained when key decision-making is made integrating stakeholders at other levels of vertical governance (e.g. local, regional and national).

- Multi-stakeholder decision-making process. Alternative approach to basic stakeholder engagement, this approach is being tested by many cities to target specific stakeholder groups through the formation of climate action committees and task forces. The approach aims to close the diversity of interests and positions, not only to further democratic principles but also to increase the possibility that the proposed actions and plans will be accepted, implemented and effective. Used in many plans, such as the development of green, low-emission and climate-resilient development strategies (Green LECRDS) to 
legitimize the process and secure political support in order to implement eventual strategy, listed in the Guidebook by UNDP [15], since now it have been relatively successful at gaining strong commitments from small groups of local inhabitants to volunteer their time and assist in the planning process [16].

- Community-based adaptation (CBA). Often targeted to poor communities and widely used in the global South, CBA integrates governance approaches and tools for participatory planning. CBA is emerging as a means for promoting engagement in assessments, fostering community self-reliance, and raising awareness of vulnerability to climate impacts in areas such as disaster planning and public health [16]. CBA is in fact considered very relevant given that climate change impacts are highly context specific and should be informed by local knowledge and experience. Where community-level actions can be mainstreamed into, and supported by, city-level planning mechanisms, this creates the potential for more effective risk reduction whilst building capacity, devolving authority to the community level, enhancing governance and accountability [17].

- Co-design, co-production and community engagement. The approach encompasses: traditional forms of community engagement, participatory planning and design (workshops, town meetings, OST etc.) to reach common goals and objectives which result in reciprocal advantages for the participants and, ideally, for the local community as a whole; other world spreading approaches, such as Placemaking (e.g. Project for Public Space), a multifaceted approach to the planning, design and management of public spaces which actively involved the local community also in the co-production of public space; and emerging ones, as Tactical Urbanism, based on short-term actions to create immediate change in urban context.

- Urban Commons co-management. Linked to concepts such as 'sharing city', horizontal subsidiarity and polycentrism, the approach prompts governments to look for, and accept, allies to share the responsibility of caring for common goods with an active citizenry. Foster and Iaione [18] establishes that this "sharing" implies that citizens are willing to act for the general interest - to be a city-maker rather than just a city-user. Instead of trying to solve a large and diffuse issue (e.g. climate change) by themselves, governments look for and facilitate the initiatives of proactive citizens who, individually or in groups, are willing to take direct care of the commons.

- Transition Towns. A Transition Town or transition initiative is a grassroots community project that seeks to build resilience in response to peak oil, climate destruction, and economic instability by creating local groups that uphold the values of the transition network. One of the basics of transition theories is that the presence of persistent problems rooted in different social environments, are highly difficult to resolve and manage in a traditional way and require innovation and the adoption of radical transformation of the current system. Transition Towns movement started in UK in 2006, in the small town of Totnes, Devon, and has since spread to over 300 communities in the UK as well as to US, Australia, Japan and Chile [19].

- $\quad$-Resilience. In a context of rapidly spreading of use of information and communication technologies (ICTs), these tools offer an important development potential particularly in for low income populations whose existing vulnerabilities are magnified by the effects of climate related disturbances, creating new opportunities. Ospina and Heeks [20] defines e-Resilience as a property of livelihood systems by which ICTs interact with a set of resilience qualities, enabling the system to adapt to the effects of climate change. 
Table 1: Leading actors in climate change experiments in global cities.

\begin{tabular}{|c|c|c|}
\hline Leading actor(s) & Approach used & Example \\
\hline \multirow{2}{*}{$\begin{array}{l}\text { Municipality or other } \\
\text { level of government }\end{array}$} & $\begin{array}{l}\text { Multi-stakeholder decision- } \\
\text { making process }\end{array}$ & $\begin{array}{l}\text { Chicago Climate Action Plan } \\
\text { (CCAP) }\end{array}$ \\
\hline & Multi-level process & Rotterdam Climate Proof (RCP) \\
\hline \multirow{2}{*}{$\begin{array}{l}\text { Public-private part- } \\
\text { nership }\end{array}$} & $\begin{array}{l}\text { Community-based adaptation } \\
\text { (CBA) }\end{array}$ & $\begin{array}{l}\text { Oakland Community Based } \\
\text { Adaptation Planning }\end{array}$ \\
\hline & $\begin{array}{l}\text { Co-design and co-production } \\
\text { engagement process }\end{array}$ & $\begin{array}{l}\text { Copenhagen (Østerbro) Climate } \\
\text { Quarter }\end{array}$ \\
\hline \multirow{3}{*}{$\begin{array}{l}\text { Civil society grass- } \\
\text { roots initiative }\end{array}$} & Transition Towns & Totnes Transition in action \\
\hline & $\begin{array}{l}\text { Transition and Urban } \\
\text { Commons co-management }\end{array}$ & Milano "Free Urban Turnips" \\
\hline & e-Resilience & Senigallia Community SOS \\
\hline
\end{tabular}

The different approaches can be used in different contexts related to who leads the urban 'climate change experiment', as shown in the previous Table 1.

\section{RESILIENT CITIES AND COMMUNITIES IN ACTION: A METHODOLOGICAL APPROACH}

European cities face the challenge of sustainable urban transformation from within their historic city fabric, undergoing a critical period and experiencing a time of fragility [21]. In order to maintain identities and values that urban environment represents, it is crucial to address the issues below at both local and European level. Tailored but replicable interventions could support a sustainable and smart growth into the urban context combining effective measures to valorise historic built environment, existing city infrastructure and local socioeconomic use patterns.

The paper illustrates the methodology developed by the Research Unit of the Department of Architecture for the enhancement of resilience in historic city centre, following a multiactor approach, crucial for improving the sense of place between the communities, and for increasing their active participation in the transition to more sustainable and liveable urban areas. This approach considers historic city heritage as a common good, capable of generating new social, economic and environmental processes combining ordinary and extraordinary developments.

Historical city centres constitute a very interesting field to experiment new regeneration formulas: their compact high density urban texture allows that in a limited space coexist a significant concentration of people, activities, jobs, relationships, with multiple and crossed functions (residents together with visitors, independent retailers along with global store chains, museums, theatres, university areas, public services, etc.), but often afflicted by alterations and degradation phenomena due to social decay, lack of security, non-effective management of spaces, difficulties in the application of mitigation and adaptation measures in the urban fabric, lack of social cohesion and environmental awareness, underused open spaces, low engagement of the communities. All these barriers increase the vulnerability of the historic cities, caused by the intersection of human systems and the built environment. 
The challenge is to bridge the gap between heritage conservation and contemporary issues, such as sustainability, competitiveness, social cohesion and creativity, with a cross-disciplinary spatial approach.

The main objective is to develop a light social infrastructure with viable working process and organization for collaboration towards a sustainable city over a long period of time. The more hands-on activities include the strengthening of existing regeneration projects integrating them with new ones, testing new ways to move from demonstration to large-scale implementation and promote the export and acceptance of technology and services between communities.

The methodological approach developed fosters the transition towards low-carbon historic city-centers, based on horizontal integration, a mix of top-down planned elements and emergent, self-organized activities coalescing into a model of local development. The focus is on the entire urban morphology, with the aim to provide the opportunity to revitalize not only the physical dimension of a city, but also the economic and social ones.

The aims of the research are:

1. identifying the priority characteristics of resilience for a target community;

2. assessing the communities' achievement of these characteristics also during crisis/disaster events;

3. identifying the characteristics and strategies of resilient historic city;

4. defining the most highly rated interventions or services in building local resilience.

At the beginning of the project, an inventory of significant players and social factors will be drafted, then characterization models for translating social and inventory data into subcategory (based on competences, role, communication, resources, etc.) results will be developed.

The research study maps out holistic and multi-dimensional issues facing the historic city that cannot be addressed by any single organisation, programme or sector. Consequently, the research findings can be of relevance to a wide range of actors working in these urban areas.

The second step is the implementation of a long-term plan of engagement of citizens of the historic city centre to build up consensus on the project and implement a process of citizens democratic participation to its realization, analyse the user acceptance of the proposed sustainable and resilient solutions at district level, co-design with citizens and stakeholders ideas for new solutions to face the neighbourhood challenges.

The social infrastructure will exploit the main principles of co-creation and will rely on the implementation of localised infrastructures like networks of stakeholders that share a problem and actively coproduce its solution(s) by exploiting different forms of innovation and economies: social and technological innovation, sharing and collaborative services, collaborative decision making.

The third step is the implementation of the methodology, testing in the operational environment strategies and tools to improve sustainability and resilience of the management of historic city. Permanent and temporary initiatives will follow an integrated management plan for sustainable historic urban context (i.e. carbon neutral cultural events, slow mobility, sustainable approaches for heritage-led regeneration). The creation of social infrastructure for historic cities supports the integration between environmental and sustainable growth to enhance local development and regeneration, moving from a proactive engagement of the communities. 
After the definition of the target group to involve in the social infrastructure it will be possible to identify the most effective initiatives for the implementation phase. Following, some examples:

1. SMEs: Co-design an eco-incubator with local partners: pointing up business model, fundraising and communication campaign, to boost creation of green businesses at local level. Through organizing and facilitating a multi-stakeholder co-creation workshop is it possible to build synergies among actors, and outline a common vision to foster the local green economy, drafting a white paper as a result. Co-design a green business network with local partners: member services, business model, online platform, legal form, funding, partnerships, roadmap and launching campaign. Interconnect the network with international counterparts: bridging platforms, joint green business summits, innovation transfer, research projects, etc. Once a critical mass of green businesses exists in the region, then a green business network that generates high added-value for its members can greatly contribute to scale up their impact.

2. Students: Green Office, a student-led and staff-supported sustainability hub that coordinates and initiates a dynamic change process towards sustainability within local institutions. The structure drives the sustainability transition of the university, by creating new impulses, connecting and empowering actors, improving communications or developing sustainability strategies, in close collaboration and partnership with internal and external stakeholders.

3. Communities of practices: Resilience Living Lab, long term- oriented and build on existing structures and institutions.

\subsection{The case of Bologna}

The demonstration case is an area of the historic city centre of Bologna, which is characterized by a high value heritage fabric affected by different categories of criticism:

- Concerning climate: flooding and heat waves especially during the summer season;

- Concerning social aspects: environmental and social decay, rapid demographic change, no-integrated immigration, political disengagement, depopulation of the historic centre, micro-crimes.

The pilot area is a very interesting urban context with a mix of functions: Universities, housing, retailers, historic ateliers and shops. The objective of the Municipality and the University (which have signed an agreement to transition the demonstration area into a safer and more-liveable cultural and creative district) is the transformation of this area into a Sustainable Cultural and Creative District (Zamboni SCCD) (Fig. 1) by improving safety, mitigating social conflicts, attracting visitors and tourists, entrepreneurs and private investments.

The aim is to develop co-designed cultural and sustainable initiatives in this area; to increase pedestrian flows and slow mobility with new cultural routes; to enhance porticoes as a unique spatial experience of the city and adopt digital solutions to improve communication and knowledge sharing, for the effective transformation into a low-carbon district.

The RU is engaged in the definition of a feasibility study for the transformation of this area into a low-carbon cultural and sustainable historic district, moving from a well structured regulatory framework: 


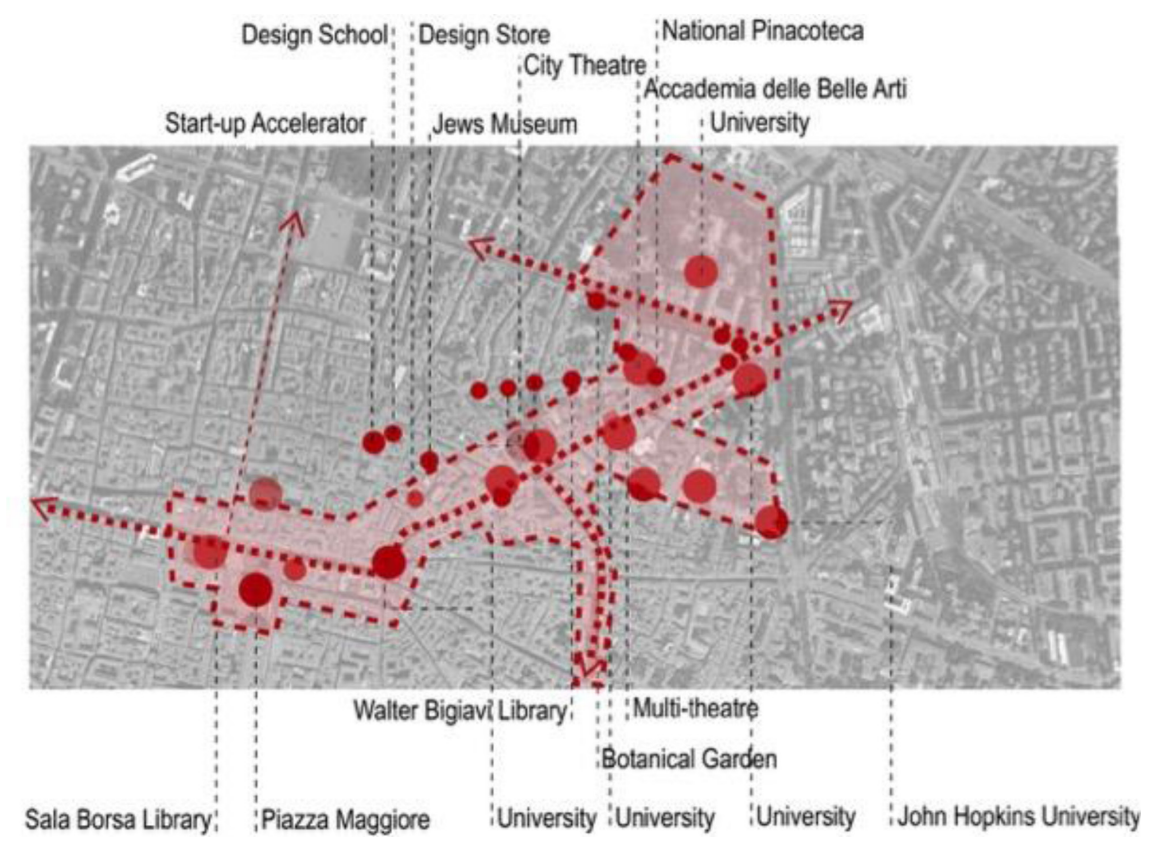

Figure 1: Zamboni area.

- The Local Urban Environment Adaptation Plan for a Resilient City (funded by BlueAP LIFE + project) that foresees the definition of pilot actions to promote the active participation of stakeholders for the acceleration of its strategy and different initiatives;

- The Bologna Regulation for the Care and Regeneration of the Urban Commons

- To coordinate and collect a set of on-going projects and actions, with the participation of companies and local actors.

Some of the on-going projects promoted by/in the city (Incredibol!, Instabile Portazza, just to name a few) are aimed at creating spaces to support creative businesses in innovation projects, or becoming places of encounter and collaboration for creative communities and local community, configured as service spots for the socio-economic development of the city, in a broader and comprehensive perspective of sustainability and resilience as 'the potential to create opportunities for doing new things, for innovation and development', as defined by Adger [22].

The potential is to configure these spaces as places to foster the participatory construction of a resilient local community able to react creatively to the changes taking place. All these initiatives, however, are punctual and pose a problem of access (do they reach everybody, especially underrepresented communities which are more vulnerable to climate change effects), effectiveness and continuity over time and space.

The challenge is to connect these elements as part of the sustainable district through soft measures (ITC, app, open source, participatory learning, assessment, co-design and co-management) and hard (additional spaces dedicated, Urban Living labs, green and blue infrastructure) that is able to support the specific task not achievable otherwise.

The core activity is the creation of Living Labs on Cultural Heritage $(\mathrm{CH})$, jointly promoted by University and Municipality, to adequately take into consideration the end-users 


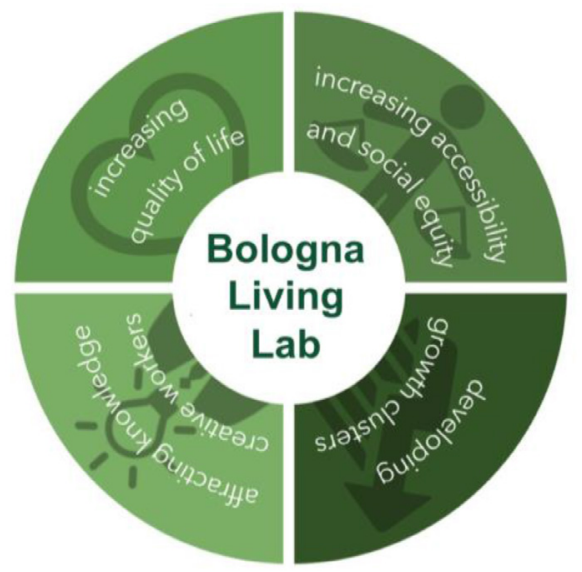

Figure 2: Living lab goals.

and target groups perception and acceptance of the historic city regeneration measures with the aim to create a constant connection between universities/enterprise/creators, supporting faster growth in community income and wealth. The Living Lab (Fig. 2) will promote the co-design of a cultural district in the historic city, intended as a sustainable model of horizontal integration (increasing levels of coordination and complementarities among firms belonging to different value chains) that leads to culture-driven forms of local economic and social development.

\section{EXPECTED OUTCOMES AND CONCLUSIONS}

The design of Bologna Living Lab on $\mathrm{CH}$ is based on a match between enabler-driven and user-driven approach, fostering a multi-party cooperation and a co-creation of value with the communities. This match will produce different outcomes:

- New cooperation opportunities (also based on PA/Citizenship/retailers agreements for the management of $\mathrm{CH}$ as a common good);

- Effective and shared policies able to accelerate the regeneration of historic city centre;

- Improvement of accessibility and social cohesion support (i.e. Active and visible participation of women and ethnic minorities in events, fairs and festivals);

- Increased awareness and participation in local decision making and wider civic engagement in historic city (i.e. immigrants networks and women associations working closely with stakeholders $\mathrm{CH}$ conservation and valorisation; collective initiatives under the $\mathrm{CH}$ Common Good agreements);

- Increasing in the attractiveness and sustainability of the areas;

- Businesses/Improvements in employment opportunities (i.e. new ancillary businesses in the areas; people in employment due to the increased economic activity in the area; prebusinesses products and services co-created in Living labs);

- New financing opportunities (shared business collaboration platform; PPPs creation).

Further research branches linked to the activation of Bologna Living Lab envisage the definition of an impact evaluation method to check in which way this approach interacts and 
influences social, environmental and economic realm of the historic city. Furthermore, an ICT tool (a web platform) is under construction to support the different activities of the Living Lab, and to enlarge the connection opportunities with other similar initiatives, supporting the building of an open-innovation networks.

\section{REFERENCES}

[1] United Nations, Department of Economic and Social Affairs (UNDESA), Population Division, World Population Prospects: The 2015 Revision, Key Findings and Advance Tables, 2015, available at Online, esa.un.org/unpd/wpp

[2] ICLEI, Resilient cities report. Proceeding of the 6th Global Forum on Urban Resilience and Adaptation, 2015.

[3] UN-HABITAT, Cities and climate change: global report on human settlements Series: Global Report on Human Settlements, Earthscan, 2011.

[4] Fairhurst, L., Introduction: describing impacts at the local level (Chapter 2). Resilient Cities. Cities and Adaptation to Climate Change - Proceedings of the Global Forum 2010, ed. K. Otto-Zimmermann, Springer, 2011.

[5] Bulkeley, H., Cities and Climate Change, Routledge: London, 2013.

[6] Gallopín, C., Linkages between vulnerability, resilience, and adaptive capacity. Global Environmental Change, 16, pp. 293-303, 2006. http://dx.doi.org/10.1016/j.gloenvcha.2006.02.004

[7] Walker, B., Holling, C.S., Carpenter, S.R. \& Kinzig, A., Resilience, adaptability and transformability in social-ecological systems. Ecology and Society, 9(2), p. 5, 2004.

[8] Folke, C., Carpenter, S.R., Walker, B., Scheffer, M., Chapin, T. \& Rockström, J., Resilience thinking: integrating resilience, adaptability and transformability. Ecology and Society, 15(4), p. 20, 2010.

[9] Keck, M. \& Sakdapolrak, P., What is social resilience? lessons learned and ways forward. Erdkunde - Archive of Scientific Geography, 67(1), pp. 5-19, 2013.

[10] ARUP, City Resilience Framework. City Resilience Index, Ove Arup \& Partners International Limited, 2014.

[11] Stockholm Resilience Centre, Applying resilience thinking. Seven principles for building resilience in social-ecological systems, available at Online www.stockholmresilience.org/download/18.10119fc11455d3c557d6928/1398150799790/ SRC+Applying+Resilience+final.pdf

[12] De Boer, Y., Keynote Speech, Sustainable Development in Times of Crises - Opposition or Opportunity, Bonn, 23 November 2009.

[13] Bulkeley, H. \& Newell, P.J., Governing Climate Change, Routledge: London, 2010.

[14] Castán Broto, V. \& Bulkeley, H., A survey of urban climate change experiments in 100 cities. Global Environmental Change, Elsevier Ltd, 23(1), pp. 92-102, 2013. http://dx.doi.org/10.1016/j.gloenvcha.2012.07.005

[15] UNDP, Multi-Stakeholder Decision-Making. A Guidebook for Establishing a MultiStakeholder Decision-Making Process to Support Green, Low-Emission and ClimateResilient Development Strategies, Ed. Caitlin Connelly, 2012.

[16] Anguelovski, I. \& Carmin, J., Something borrowed, everything new: Innovation and institutionalization in urban climate governance. Current Opinion in Environmental Sustainability, 3, pp. 169-175, 2011. http://dx.doi.org/10.1016/j.cosust.2010.12.017 
[17] Archer, D., Almansi, F., Di Gregorio, M., Roberts, D., Sharma, D. \& Syam, D., Moving towards inclusive urban adaptation: approaches to integrating community-based adaptation to climate change at city and national scale. Climate and Development, 6(4), pp. 345-356, 2014.

http://dx.doi.org/10.1080/17565529.2014.918868

[18] Foster, S. \& Iaione, C., The city as a commons. Yale Law \& Policy Review, 34(2), 2016.

[19] Bulkeley, H., Castán Broto, V., Marvin, S. \& Hodson, M., Cities and low carbon transitions. The European Financial Review, pp. 24-27, 2011.

[20] Ospina, A.V. \& Heeks, R., Linking ICTs and Climate Change Adaptation: A Conceptual Framework for eResilience and eAdaptation, Canada's International Development Research Centre, 2010.

[21] European Commission, Directorate General for Regional Policy, Cities of tomorrow Challenges, visions, ways forward, European Union, 2011.

[22] Adger, W.N., Vulnerability. Global Environmental Change, 16, pp. 268-281, 2006. http://dx.doi.org/10.1016/j.gloenvcha.2006.02.006 